\title{
Consumer acceptance of natural sweeteners in protein beverages
}

\author{
M. N. Parker, K. Lopetcharat, and M. A. Drake ${ }^{1}$ \\ Department of Food, Bioprocessing, and Nutrition Science, Southeast Dairy Foods Research Center, North Carolina State University, \\ Raleigh 27695
}

\section{ABSTRACT}

Protein beverage consumption by Americans has increased in recent years. Coupled with this increased consumption is an interest in natural sweeteners. The objective of this study was to evaluate the sensory properties of naturally sweetened ready-to-mix (RTM) whey protein beverages using 3 temporal methods and to formulate a natural noncaloric sweetener blend that could be added to RTM protein beverages to provide sweetness while still appealing in flavor to consumers. Iso-sweet concentrations of sweeteners (sucralose, sucrose, fructose, stevia, monk fruit) in RTM vanilla whey protein beverages $(25 \mathrm{~g}$ of protein/360 $\mathrm{mL}$ of water) were established using magnitude estimation scaling and 2-alternative forced-choice testing. Temporal sensory profiling was then conducted on each beverage by a trained panel using time intensity, temporal dominance of sensations, and temporal check-all-that-apply. These findings were used to formulate natural sweetener blends that closely matched the temporality of sucrosesweetened RTM vanilla protein beverages for consumer testing. One sugar-free blend (25\% stevia/75\% monk fruit) and 1 reduced-sugar blend (25\% stevia/25\% monk fruit $/ 50 \%$ fructose) were selected for consumer testing ( $\mathrm{n}=150$ consumers) in addition to 3 control RTM beverages containing sucralose, stevia, or monk fruit. Two distinct consumer clusters were identified. The label-conscious segment of consumers preferred beverages sweetened with natural blends when primed. The flavor-driven segment of consumers conceptually preferred naturally sweetened beverages but preferred sucralose-sweetened beverages when primed. An allnatural label claim was most preferred across all consumers. Application of these findings to commercially produced RTM protein beverages aids in the development of naturally sweetened protein beverages with reduced calories and desirable sensory properties and

\footnotetext{
Received March 6, 2018.

Accepted April 26, 2018.

${ }^{1}$ Corresponding author: Maryanne_drake@ncsu.edu
}

highlights the importance of label claims to consumers overall but to a label-conscious segment of consumers in particular.

Key words: protein beverage, natural sweetener, consumer acceptance

\section{INTRODUCTION}

Protein beverages have increased in popularity among American consumers in recent years as more Americans aim to increase their dietary protein intakes (Gerdes, 2012; Jacobson, 2015). One of the most common protein sources for protein beverages is whey protein, in the form of either whey protein concentrate 80 or whey protein isolate (WPI). Both products are produced from membrane filtration of liquid whey (Foegeding and Luck, 2011). Whey proteins are a complete source of essential AA and are high in branched-chain AA that may aid in muscle recovery after exercise, making it an ideal protein source in protein beverages (Blomstrand and Saltin, 2001; Hazen, 2003; Childs et al., 2008).

Previous research has demonstrated the importance of naturally sweetened protein beverages with low carbohydrate content to consumers (Gerdes, 2012; Jacobson, 2015; Oltman et al., 2015). However, sweet taste is also a desirable attribute to many consumers, and direct sugar removal may negatively affect consumer liking. Previous literature demonstrated a threshold for direct sugar removal of 25 to $40 \%$ in various dairy products without negatively affecting consumer acceptance (Cadena et al., 2012; Chollet et al., 2013; Hoppert et al., 2013; Li et al., 2015; Oliveira et al., 2015). Beyond this threshold, nonnutritive alternative sweeteners can be used to replace sugar and maintain sweet taste.

Natural nonnutritive sweeteners are derived from plants and comprise natural compounds, typically sweet glycosides (Kim and Kinghorn, 2002). Siraitia grosvenorii (monk fruit) is a fruit native to southern China that contains sweet glycosides mogroside IV, mogroside V, and mogroside VI (Kinghorn and Compadre, 2001; Pawar et al., 2013). Stevia, another natural sweetener, is composed of sweet glycosides stevioside and rebaudioside A (Kinghorn et al., 2001). To best formulate 
sucrose replacement with alternative sweeteners, the sweetness equivalence (iso-sweetness), or the amount of alternative sweetener that produces the same sweetness intensity, must first be determined. Magnitude estimation scaling (MES) followed by descriptive analysis and 2-alternative forced-choice (2-AFC) testing is one set of methods to confirm sweet taste equivalency (Cardello et al., 1999; Lawless and Heymann, 2010; Li et al., 2015).

Although alternative sweeteners are useful for reducing sugar, carbohydrate, and calorie content, they may have a different sweetness temporality compared with sucrose at iso-sweetness and may may contain undesirable off flavors such as bitter or metallic tastes (Kim and Kinghorn, 2002; Souza et al., 2013; Morais et al., 2014; Zorn et al., 2014). As such, sensory documentation of the temporality of sweet taste as well as the presence and temporality of other flavors or tastes associated with nonnutritive sweeteners is important when replacing sugar. Previous studies have evaluated sweeteners in food and beverage products using temporal sensory methodologies (Palazzo et al., 2011; Souza et al., 2013; Morais et al., 2014; Zorn et al., 2014; Azevedo et al., 2015). These methods have also been used for other food products such as hot beverages, flavored gels, red wine, and dairy products (Le Reverend et al., 2008; Labbe et al., 2009; Meillon et al., 2009; Pineau et al., 2009; Castura et al., 2015).

The majority of previous studies have focused on artificial nonnutritive sweeteners, whereas relatively little work has been done to investigate and characterize the temporality of natural nonnutritive sweeteners. In addition, there has yet to be a study that investigates how the addition of alternative sweeteners to whey protein beverages affects their sensory properties. The objective of this study was to profile the sensory properties of ready-to-mix (RTM) whey protein beverages sweetened with the natural sweeteners stevia, monk fruit, and crystalline fructose and blends of these sweeteners using 3 temporal methods: time intensity $(\mathbf{T I})$, temporal dominance of sensations (TDS), and temporal check-all-that-apply (TCATA). Through temporal sensory evaluation of these beverages, the ultimate goal was to formulate a natural sweetener blend that could be added to RTM protein beverages to provide sweetness without added sugar, calories, or carbohydrates and that was still desirable to consumers.

\section{MATERIALS AND METHODS}

\section{Experimental Overview}

Ready-to-mix vanilla whey protein beverages were formulated with iso-sweet concentrations of 5 sweeten- ers (sucralose, sucrose, fructose, stevia, and monk fruit). Iso-sweetness was confirmed in each beverage with MES and 2-AFC testing. Sweetened beverages were profiled using descriptive analysis and temporal sensory profiling methods (TI, TDS, and TCATA) with trained panels. These results were used to formulate natural sweetener blends that closely matched the temporality of sucrose-sweetened RTM vanilla protein beverages. Of the 7 natural sweetener blends, 1 sugar-free blend and 1 reduced-sugar blend were selected for consumer testing against 3 control RTM beverages sweetened with sucralose, stevia, or monk fruit. Consumers (n $=150$ ) evaluated beverages with and without priming statements in a 2-d crossover design test.

\section{Sample Preparation}

Protein beverages were prepared according to a common industry formulation to contain either 15 or $25 \mathrm{~g}$ of protein per $360 \mathrm{~mL}$ of water (Table 1). Two commercial sources of WPI (Cheddar, microfiltration, Northwest commercial supplier; Cheddar, anion exchange, Midwest supplier) were used to make RTM protein beverages. Both WPI met the legal definition of WPI (at least $90 \%$ protein). Beverages were formulated with WPI, deionized (DI) water, sweetener, and vanilla flavoring (natural vanilla 1032, natural cream 0151, natural French vanilla 1068; Flavor Artistry, Corona, CA). Both WPI sources were obtained directly from the plant as spray-dried powders within $30 \mathrm{~d}$ of production and stored at $-80^{\circ} \mathrm{C}$ throughout the duration of the study. Sucrose (Imperial Sugar Co., Sugar Land, TX), crystalline fructose (Krystar 300; Tate \& Lyle, Decatur, IL), sucralose (Hard Eight Nutrition, Henderson, NV), monk fruit extract (Purefruit Select monk fruit extract; Tate \& Lyle), and stevia leaf extract (Tasteva stevia sweetener; Tate \& Lyle) were added as sweeteners to the RTM vanilla protein beverage base. All sensory testing was approved as exempt by the North Carolina State University Institutional Review Board for human subjects.

\section{Power Function Curves of Natural Nonnutritive Sweeteners in Water, Protein Base, and Vanilla- Flavored Protein Beverages}

Power function curves were generated for stevia, monk fruit, fructose, and sucralose in DI water, WPI solution (15 or $25 \mathrm{~g}$ of protein/360 mL of DI water), and vanilla-flavored WPI beverages (15 or $25 \mathrm{~g}$ of protein/360 $\mathrm{mL}$ of DI water) by trained panelists (n $=8 ; 5$ women, 3 men, ages $22-30 \mathrm{yr}$ ). Each panelist had a minimum of $40 \mathrm{~h}$ of previous descriptive analysis 
experience using the Spectrum method (Meilgaard et al., 2007) with an additional $6 \mathrm{~h}$ of training with MES.

Magnitude estimation scaling was used to build power function curves for each sweetener at both high and low protein levels for each WPI source. The MES curves were first established for each sweetener in water only as a training exercise. Next, curves were determined for each sweetener in a WPI solution at each protein level (15 or $25 \mathrm{~g}$ of protein/360 mL of DI water) and for each protein source (microfiltered or anion exchange) to investigate differences in iso-sweet values between protein levels and sources. Last, curves were determined for vanilla-flavored WPI beverages at each protein level.

For MES exercises, a $7 \%$ sucrose solution was used as the reference sweet solution and was assigned an arbitrary value of 100 . The reference sweetness intensity was chosen based on a category screening of commercial vanilla-flavored RTM and ready-to-drink protein beverages. Samples were served at $21^{\circ} \mathrm{C}$ as $30-\mathrm{mL}$ aliquots in lidded 60-mL soufflé cups labeled with random 3-digit codes. Serving order was randomized within each session, and each replicate of each series was evaluated in a separate session. Panelists were instructed to taste each sample against the reference solution and assign a ratio score based on the sample's relative sweetness compared with the reference. Panelists expectorated solutions. Each MES series contained 7 samples that covered a concentration range from detectable sweetness to well above the sucrose reference. Concentration ranges and factors were determined based on previous literature values (Cardello et al., 1999; Savita et al., 2004; Reis et al., 2011; Lisak et al., 2012; Morais et al., 2014; Zorn et al., 2014; Azevedo et al., 2015; Li et al., 2015). A 5-min rest was enforced between samples, during which panelists rinsed with DI water. All series were evaluated in triplicate by each panelist using paper ballots.

\section{Determination and Confirmation of Iso-Sweetness Values in Vanilla-Flavored Protein Beverages}

Descriptive analysis was used to confirm and adjust iso-sweetness values from MES (Li et al., 2015). No significant differences in iso-sweetness values were documented between protein amounts (15 vs. $25 \mathrm{~g} / 360$ $\mathrm{mL}$ of DI water) or protein source (microfiltration vs. anion exchange) in MES $(P>0.05)$, so all beverage formulations were confirmed using $25 \mathrm{~g}$ of microfiltered WPI/360 mL of DI water with and without vanilla. A trained panel evaluated each sweetened protein beverage in duplicate compared with the $7 \%$ sucrose reference (described later).

Iso-sweetness values for sweetened vanilla protein beverages were also confirmed with 2-AFC testing ( $\mathrm{n}$ $=40$; ASTM International, 2008; Li et al., 2015). Untrained consumers $>18$ yr were recruited from the Sensory Service Center (Raleigh, NC) database. Samples of vanilla-flavored protein beverage sweetened with stevia, monk fruit, sucralose, or fructose were evaluated against a reference vanilla protein beverage sweetened with $70 \mathrm{~g}$ of sucrose/L. Consumers were instructed to taste the samples from left to right and select the sample they thought was sweeter. Samples were served as $20-\mathrm{mL}$ aliquots in lidded $60-\mathrm{mL}$ soufflé cups labeled with random 3 -digit codes at $21^{\circ} \mathrm{C}$. Presentation order was balanced within and between sample pairs (Meilgaard et al., 2007), with stevia always served in the last position due to lingering sweetness (DuBois and Prakash, 2012). Up to 3 sample pairs were tested in each session. A 5-min rest was enforced between each pair, during which panelists rinsed with DI water and unsalted crackers. All data were collected using Compusense Cloud software (Compusense, Guelph, ON, Canada).

\section{Formulation of Natural Sweetener Blends}

Results from power function curves and iso-sweetness confirmation for individual sweeteners were used to formulate 7 natural sweetener blends consisting of monk fruit, stevia, or fructose (blend $1=25 \%$ stevia $/ 75 \%$ fructose; blend $2=25 \%$ monk fruit $/ 75 \%$ fructose; blend $3=50 \%$ stevia $/ 50 \%$ monk fruit; blend $4=25 \%$ stevia $/ 25 \%$ monk fruit $/ 50 \%$ fructose; blend $5=50 \%$ stevia $/ 50 \%$ fructose; blend $6=50 \%$ monk fruit $/ 50 \%$ fructose; blend $7=25 \%$ stevia $/ 75 \%$ monk fruit). Blends were divided into 2 categories: reduced sugar (blends 1 , 2, 4, 5, and 6) and sugar free (blends 4 and 7). Each blend was added to the vanilla-flavored protein beverage base. Iso-sweetness of blends to a $7 \%$ sucrose solution were again confirmed using descriptive analysis and 2-AFC testing as previously described $(\mathrm{n}=40)$.

Table 1. General formulation of vanilla ready-to-mix whey protein beverages at high and low protein levels per 360-mL serving size

\begin{tabular}{lcccc}
\hline $\begin{array}{l}\text { Protein per } \\
\text { serving }(\mathrm{g})\end{array}$ & $\begin{array}{c}\text { Whey protein } \\
\text { isolate powder }(\mathrm{g})\end{array}$ & $\begin{array}{c}\text { Natural vanilla } \\
\text { flavor }(\mathrm{g})\end{array}$ & $\begin{array}{c}\text { Natural cream } \\
\text { flavor }(\mathrm{g})\end{array}$ & $\begin{array}{c}\text { Natural French } \\
\text { vanilla flavor }(\mathrm{g})\end{array}$ \\
\hline 15 & 16.8 & 0.60 & 0.45 & 0.15 \\
25 & 28.0 & 0.60 & 0.45 & 0.15 \\
\hline
\end{tabular}




\section{Descriptive Analysis}

Descriptive analysis using the Spectrum method (Meilgaard et al., 2007) was conducted to evaluate protein beverages sweetened with sucrose, fructose, sucralose, monk fruit, stevia, and the 7 natural blends of fructose, monk fruit, and stevia. Samples were evaluated with and without vanilla flavoring to determine the effect of the vanilla flavor on sweet taste. All samples were evaluated in triplicate by a trained descriptive panel consisting of 8 trained panelists (all female, ages 22-55 yr). Each panelist had a minimum of $40 \mathrm{~h}$ of descriptive analysis training using the Spectrum method (Meilgaard et al., 2007) and at least $40 \mathrm{~h}$ of additional experience documenting the sensory properties of dairy products, including protein beverages (Russell et al., 2006; Wright et al., 2006; Drake et al., 2009). Samples $(45 \mathrm{~mL})$ were served at $21^{\circ} \mathrm{C}$ in lidded $60-\mathrm{mL}$ soufflé cups labeled with random 3-digit codes. A 5-min rest was enforced between samples. Attributes scored were aroma intensity, vanilla flavor, cardboard flavor, bitter taste, sweet taste, metallic taste, astringency, and aftertaste intensity. Paper ballots were used.

\section{Temporal Sensory Evaluation Methods}

The temporal sensory properties of vanilla-flavored RTM protein beverages sweetened with sucrose, fructose, stevia, monk fruit, sucralose, and natural sweetener blends were investigated by trained panelists. All samples were served at $21^{\circ} \mathrm{C}$ as 15 -mL aliquots in lidded 60-mL soufflé cups labeled with 3 -digit codes. Preparation occurred $1 \mathrm{~d}$ before testing by mixing all dry ingredients, rehydrating with DI water, and pouring into sample cups. All data were collected in triplicate on iPads (Apple, Cupertino, CA) using Compusense Cloud software. Panelists were instructed to press the start button, immediately place the entire sample in their mouths, and begin evaluation. Instructions to expectorate were shown at $12 \mathrm{~s}$. A rest period of 5 min was enforced between samples, during which panelists were instructed to rinse with DI water and unsalted crackers. Two separate panels were used: 1 for TI evaluation and 1 for TDS and TCATA evaluations. The TI panelists ( $\mathrm{n}=8$; 1 man, 7 women; ages $24-55 \mathrm{yr}$ ) had at least 80 $\mathrm{h}$ of prior descriptive analysis experience and at least $30 \mathrm{~h}$ of previous experience with TI methodology and evaluation. The TDS and TCATA panelists $(\mathrm{n}=8 ; 4$ men, 4 women; ages 22-35 yr) also had prior descriptive analysis experience $(>80 \mathrm{~h}$ each) and participated in two 30-min instruction and practice sections for each temporal method before beginning data collection. For each method, up to 4 beverages were evaluated per session.
TI. Throughout the evaluation, panelists were instructed to move a cursor to the appropriate intensity level for the attribute using a 0- to 15-point Spectrum scale (Meilgaard et al., 2007). Evaluation took place over $100 \mathrm{~s}$. Attributes of sweet, bitter, and metallic were evaluated for each sample on separate days. Before beginning evaluation, panelists warmed up with appropriate reference solutions [5, 7, and $9 \% \mathrm{wt} / \mathrm{wt}$ sucrose solutions (sweet taste); $0.5 \%$ wt/wt caffeine solution (bitter taste); or $0.4 \% \mathrm{wt} / \mathrm{wt}$ copper sulfate solution (metallic taste)].

TDS. Panelists were instructed to select the single attribute perceived as dominant at any point during the evaluation period (Pineau et al., 2009). Unlimited selections as well as reselections were allowed. The attributes sweet, bitter, metallic, sweet aromatic, cardboard, and none were displayed simultaneously on the iPad interface. After the point at which no sensations were perceived, panelists were instructed to select "none." Evaluation took place over $192 \mathrm{~s}$.

$\boldsymbol{T C A T A}$. Temporal check-all-that-apply followed the same evaluation procedure as TDS except that selection of multiple attributes at one time was allowed (Castura et al., 2015). The attributes displayed simultaneously were sweet, bitter, metallic, sweet aromatic, cardboard, and none. Unlimited selections and reselections were allowed for all applicable attributes, and panelists were instructed to select "none" when sensations were no longer perceived. Attributes were not scaled for intensity.

\section{Consumer Acceptance Testing}

Subsequently, a central location test was conducted at North Carolina State University to investigate consumer liking and acceptance for vanilla-flavored RTM whey protein beverages sweetened with natural sweeteners and selected sweetener blends. Beverages (5 total) were sweetened with sucralose, monk fruit, stevia, a sugar-free stevia/monk fruit blend (25:75; blend 7), and a reduced-sugar monk fruit/stevia/fructose blend (25:25:50; blend 4$)$. Consumers $(\mathrm{n}=150)$ evaluated the 5 sweetened protein beverages with and without priming statements in a 2 -d crossover design test ( $\mathrm{Li}$ et al., 2015; Hubbard et al., 2016). Test days were separated by $4 \mathrm{wk}$ to prevent memory effects. Half of consumers read priming statements before tasting each sample for each testing day. The other half of consumers evaluated the same beverages and answered the same questions without seeing priming statements. The order of test days (primed vs. unprimed) was randomly assigned.

Consumers were recruited from a database of $>8,000$ respondents maintained by the Sensory Service Center (North Carolina State University, Raleigh). Consumers were required to be 18 to 54 yr of age, self-reported 
exercisers (once a week or more), self-reported RTM protein powder consumers (at least 2 times per month), and vanilla flavor acceptors. Additionally, respondents were required to have an awareness of nonsucrose sweeteners in products they consumed (report consumption of nonsucrose sweeteners at least once in past $3 \mathrm{mo}$ ). Participants were compensated with a gift card after completion of the second testing day.

Sample beverages contained $25 \mathrm{~g}$ of protein $/ 360$ $\mathrm{mL}$ of DI water, as this concentration was similar to protein concentrations in rehydrated commercial RTM protein powders. Dry ingredients were weighed, mixed, and stored in airtight containers $12 \mathrm{~h}$ before tests. Dry mixes were rehydrated in $500 \mathrm{~mL}$ of DI water (kept at $\left.4^{\circ} \mathrm{C}\right) 15$ min before serving using shaker bottles with metal blender balls (BlenderBottle, Lehi, UT). Aliquots $(60 \mathrm{~mL})$ were served in lidded $120-\mathrm{mL}$ soufflé cups labeled with random 3-digit codes. A 5-min rest was enforced between samples, during which panelists were instructed to cleanse their palates with DI water and unsalted crackers.

For each day of testing, consumers evaluated all samples in a complete balanced, randomized design, and data were collected using Compusense Cloud software. Consumers tasted all 5 RTM protein beverage samples each session and answered questions about overall liking, sweetness, vanilla flavor, thickness, quality, and purchase intent. Liking was scored on a 9-point hedonic scale, with $1=$ dislike extremely and $9=$ like extremely. Quality and purchase intent were scored on 5 -point scales with $1=$ extremely low quality/definitely would not purchase and $5=$ extremely high quality/ definitely would purchase. Aftertaste liking was scored only when aftertaste was indicated.

Priming statements about the sweetener used in each beverage were displayed before tasting in primed sessions. For the sucralose control, the priming statement was "The protein beverage you are about to taste is sweetened with sucralose and is sugar and carbohydrate free." For the monk fruit control, the statement was "The protein beverage you are about to taste is naturally sweetened with monk fruit extract and is sugar and carbohydrate free." For the stevia control, the statement was "The protein beverage you are about to taste is naturally sweetened with stevia leaf extract and is sugar and carbohydrate free." For natural blend 1 , the statement was "The protein beverage you are about to taste is naturally sweetened with monk fruit and stevia leaf extracts and is sugar and carbohydrate free." For natural blend 2, the statement was "The protein beverage you are about to taste is naturally sweetened with extracts from stevia leaf and monk fruit and natural fructose crystals and has $>50 \%$ less sugar than a regular sweetened protein beverage with sucrose."

\section{Statistical Analyses}

Power curves were constructed by plotting the logarithm of the geometric mean of the average response at each sweetness concentration level against the logarithm of the sample sweetener concentration (ASTM International, 2012). Following power curve generation, the iso-sweet concentrations were confirmed using the minimum number of "correct" judgments for significance through 2 -AFC testing $(\alpha=0.05$; Meilgaard et al., 2007; ASTM International, 2008). Linear regression models were generated to compare power function curves using SAS version 9.4 (SAS Institute Inc., Cary, $\mathrm{NC}$ ). Iso-sweet values between protein source and protein level for each individual sweetener (sucralose, fructose, monk fruit, and stevia) were calculated and compared using the NLMIXED procedure to fit the nonlinear magnitude estimation data.

Descriptive analysis data were analyzed using a 1-way ANOVA with means separation in XLSTAT (Fisher's LSD, $\alpha=0.05)$. The effect of protein level, protein source, and vanilla flavoring on descriptive analysis sweetness scores was analyzed separately using 2-way ANOVA (protein level $\times$ sweetener, protein source $\times$ sweetener, vanilla flavoring $\times$ sweetener) with means separation in XLSTAT (Fisher's LSD, $\alpha=0.05$ ).

Time intensity data were analyzed using an add-on macro provided by Compusense Cloud in XLSTAT version 2014.4.09 (Addinsoft, New York, NY). Parameters were extracted from the raw data and analyzed using a 1-way ANOVA with means separation in XLSTAT (Fisher's LSD, $\alpha=0.05$ ). The TDS and TCATA data were graphed using XLSTAT, and results were displayed as band plots, with attributes detected shown as horizontal bands. Significance was determined using a binomial proportion $(\alpha=0.05$; Pineau et al., 2009).

Consumer acceptance data were analyzed in XLSTAT. Liking scores were analyzed using a 1-way ANOVA with means separation (Fisher's LSD, $\alpha=$ 0.05). The 5-point questions were analyzed using the Kruskal-Wallis test with Dunn's multiple comparisons test $(\alpha=0.05)$. A 2-way ANOVA (priming $\times$ beverage type) with means separation was used to determine the effect of priming statements on liking means for each beverage (Fisher's LSD, $\alpha=0.05$ ). Consumers were grouped into clusters using k-means on differences between primed and unprimed overall liking scores across all panelists ( $\mathrm{Li}$ et al., 2015). Partial least squares regression was conducted in XLSTAT to see how bever- 
ages were characterized and how this related to liking for each consumer cluster.

\section{RESULTS AND DISCUSSION}

\section{Power Function Curves and Iso-Sweetness Values}

Results from MES and power function curve generation confirmed that sucralose was the most potent sweetener, followed by monk fruit, stevia, and fructose. Iso-sweet values were $130.7 \mathrm{mg} / \mathrm{L}$ for sucralose, 642.6 $\mathrm{mg} / \mathrm{L}$ for monk fruit, $786.5 \mathrm{mg} / \mathrm{L}$ for stevia, and 63.60 $\mathrm{g} / \mathrm{L}$ for fructose. These results are consistent with previous literature, which reported that sucralose is 500 to 600 times sweeter than sucrose, stevia is 97 to 240 times sweeter than sucrose, mogrosides IV and V are 233 to 450 times sweeter than sucrose, and fructose is up to 1.8 times sweeter than sucrose (Cardello et al., 1999; Kinghorn and Compadre, 2001; White and Osberger, 2001; Kim and Kinghorn, 2002). Minor adjustments to sweetener concentrations were required following descriptive analysis and before 2-AFC tests (Table 2).

\section{Effect of Protein Level and Protein Source on Iso-Sweetness Values}

Protein level (15 vs. $25 \mathrm{~g} / 360 \mathrm{~mL}$ serving size) and WPI type (anion exchange vs. microfiltered) had no effect $(P>0.05)$ on iso-sweetness concentration for any of the 4 sweeteners investigated in this study (fructose, sucralose, monk fruit, and stevia; results not shown). These interactions were important to investigate due to increasing consumer interest in greater dietary protein consumption (notably in the form of protein beverages) and greater protein concentration in beverages (Gerdes, 2012; Jacobson, 2015; Oltman et al., 2015). The lack of effect of WPI source on sweetness perception suggests that glycomacropeptide has no effect on sweet taste perception (microfiltered WPI contains glycomacropeptide; anion exchange WPI does not).

\section{Descriptive Analysis}

Descriptive analysis results demonstrated that vanilla flavoring did not affect sweet taste perception for any of the beverages $(P>0.05$; results not shown). Subsequent descriptive analysis results refer to beverages with vanilla flavorings using microfiltered WPI with $25 \mathrm{~g}$ of protein/360 mL. No significant differences were seen between any of the sweeteners or sweetener blends for intensities of aroma, vanilla, cardboard, sweet taste, or astringency $(P>0.05$; Table 3$)$. Cardboard flavor was detected above threshold level in all beverages, as this is a flavor that has been widely characterized in

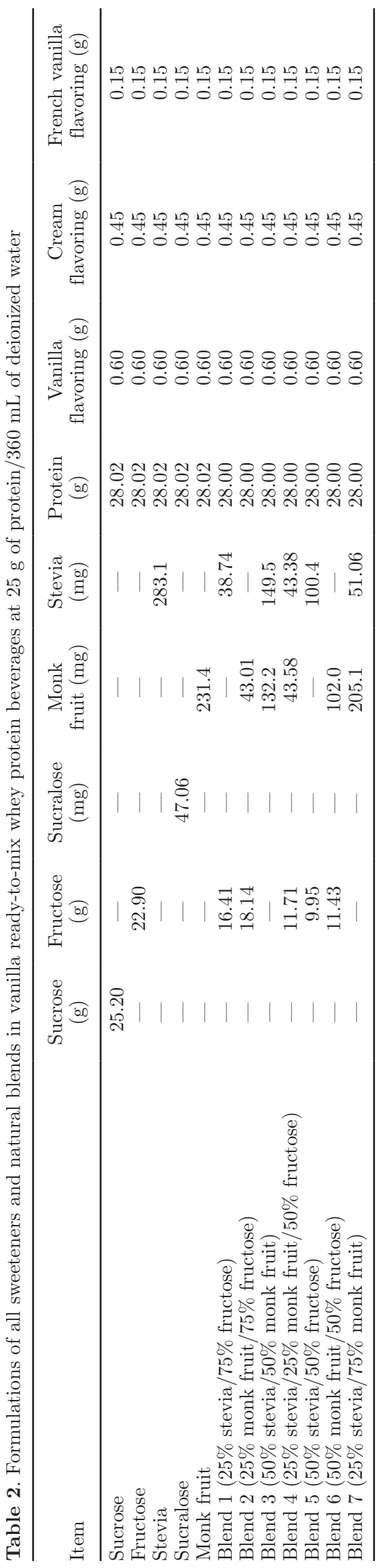


Table 3. Trained panel profiles of ready-to-mix vanilla whey protein beverages at $25 \mathrm{~g}$ of protein/360 $\mathrm{mL}$ of deionized water with different sweeteners and sweetener blends at iso-sweet taste intensities

\begin{tabular}{|c|c|c|c|c|c|c|c|c|c|c|c|c|}
\hline \multirow[b]{2}{*}{ Item } & \multirow[b]{2}{*}{ Sucrose } & \multirow[b]{2}{*}{ Fructose } & \multirow[b]{2}{*}{ Sucralose } & \multirow[b]{2}{*}{ Stevia } & \multirow[b]{2}{*}{ Monk fruit } & \multicolumn{7}{|c|}{ Blend $^{2}$} \\
\hline & & & & & & 1 & 2 & 3 & 4 & 5 & 6 & 7 \\
\hline Vanilla flavor $^{3}$ & 1.5 & 1.6 & 1.4 & 1.1 & 1.1 & 1.0 & 0.8 & 0.8 & 1.0 & 1.3 & 1.3 & 1.3 \\
\hline Cardboard flavor ${ }^{3}$ & 1.2 & 1.5 & 1.6 & 1.3 & 1.2 & 1.0 & 1.2 & 1.4 & 1.0 & 1.6 & 1.6 & 1.6 \\
\hline Bitter taste & $\mathrm{ND}^{4}$ & ND & $0.8^{\mathrm{b}}$ & $1.3^{\mathrm{a}}$ & $1.0^{\mathrm{b}}$ & ND & ND & $1.3^{\mathrm{a}}$ & ND & $0.8^{\mathrm{b}}$ & ND & $1.0^{\mathrm{b}}$ \\
\hline Sweet taste $^{3}$ & 7.0 & 6.9 & 7.0 & 7.0 & 6.9 & 7.2 & 7.0 & 7.2 & 7.2 & 7.0 & 7.1 & 7.1 \\
\hline Aftertaste intensity & $1.1^{\mathrm{b}}$ & $1.3^{\mathrm{b}}$ & $1.9^{\mathrm{a}}$ & $1.7^{\mathrm{ab}}$ & $1.9^{\mathrm{a}}$ & $1.3^{\mathrm{b}}$ & $1.1^{\mathrm{b}}$ & $1.8^{\mathrm{a}}$ & $1.1^{\mathrm{b}}$ & $1.0^{\mathrm{b}}$ & $1.3^{\mathrm{b}}$ & $1.3^{\mathrm{b}}$ \\
\hline
\end{tabular}

${ }_{\mathrm{a}, \mathrm{b}}$ Means within a row with different superscripts differ significantly $(P<0.05)$.

${ }^{1}$ Attributes were scored on a 0- to 15-point universal intensity scale (Meilgaard et al., 2007).

${ }^{2}$ Blend $1=25 \%$ stevia $/ 75 \%$ fructose; blend $2=25 \%$ monk fruit $/ 75 \%$ fructose; blend $3=50 \%$ stevia $/ 50 \%$ monk fruit; blend $4=25 \%$ stevia $/ 25 \%$ monk fruit $/ 50 \%$ fructose; blend $5=50 \%$ stevia $/ 50 \%$ fructose; blend $6=50 \%$ monk fruit $/ 50 \%$ fructose; blend $7=25 \%$ stevia $/ 75 \%$ monk fruit.

${ }^{3}$ No significant differences were documented for these attributes across samples $(P>0.05)$.

${ }^{4} \mathrm{ND}=$ not detected.

whey proteins (Drake et al., 2003; Russell et al., 2006; Oltman et al., 2015). Samples were differentiated by differences in metallic taste, bitter taste, and aftertaste intensity (Table 3). Bitter and metallic tastes were not detected in beverages sweetened with sucrose, fructose, or natural blends with $50 \%$ or less monk fruit or $25 \%$ stevia (blends 1, 2, 4, and 6). Metallic taste alone was not detected in blend 5 (50\% stevia $/ 50 \%$ fructose), although bitter taste was present above threshold level $(P<0.05)$. Beverages sweetened with sucralose, stevia, and monk fruit, blend 3 (50\% stevia/50\% monk fruit), and blend 7 (25\% stevia/75\% monk fruit) displayed both bitter and metallic tastes above threshold level, with the highest intensities of bitter taste documented in stevia and blend 3 beverages and the highest intensities of metallic taste documented in beverages sweetened with sucralose, stevia, blend 4 , and blend $7(P<$ $0.05)$.

Bitter and metallic flavors have been widely identified and characterized in sucralose, stevia, and monk fruit (Hanger et al., 1996; Goldsmith and Merkel, 2001; Kim and Kinghorn, 2002; Pawar et al., 2013; Philippe et al., 2014). Previous studies have also reported bitter and metallic off flavors in dairy products formulated with nonnutritive sweeteners (Guggisberg et al., 2011; Morais et al., 2014; Narayanan et al., 2014; Li et al., 2015). These results demonstrate the utility of blending alternative sweeteners to minimize off flavors, as blends containing $25 \%$ stevia or monk fruit did not elicit bitter or metallic tastes above threshold, and blends with stevia and monk fruit at levels of $50 \%$ did not elicit bitter taste above threshold level. Aftertaste intensity was also significantly decreased in all natural blends $(P$ $<0.05)$ with the exception of blend $3(50 \%$ stevia $/ 50 \%$ monk fruit).

\section{TI}

Time intensity parameters and curves further characterized differences in the sensory properties of the beverages. Differing sweet TI curve shapes illustrated differences in sweetness temporality (Figures 1a and b). No differences were seen for sweet taste parameters time to maximum intensity, maximum intensity, initial delay, or increasing angle between any of the beverages $(P>0.05)$. Beverages sweetened with stevia displayed the longest lingering sweetness, shown by the greatest stop time, plateau length, and area under the curve values $(P<0.05)$. Monk fruit beverages also displayed lingering sweet taste. Beverages sweetened with fructose or blends 1, 2, or 6 had the shortest lasting sweet taste. Bitter taste was not detected above threshold in beverages sweetened with sucrose, fructose, or blends 1 , 2,4 , or 6 . Stevia-sweetened beverages had the highest maximum intensity $($ mean $=3.3)$ and longest lingering bitter taste $(P<0.05$; Figure 1c). Beverages sweetened with monk fruit, blend 3, or blend 7 had the second highest intensities of bitter taste (mean $=1.9 ; P<$ $0.05)$, followed by sucralose beverages $($ mean $=1.0)$. All bitter TI curves displayed similar shapes, with maximum bitter intensity peaking in the first $30 \mathrm{~s}$ of evaluation, followed by a steady intensity decline (Figure 1c). Stevia-sweetened beverages also had the highest metallic taste intensities (mean $=1.9 ; P<0.05$ ), followed by monk fruit, blend 3 , and blend $7($ mean $=1.1)$ and then sucralose (mean $=0.60$; Figure $1 d$ ). Stevia-sweetened beverages again displayed the longest lingering metallic taste. Similar results have been reported for TI evaluation of sweeteners regarding sweet taste (Palazzo et al., 2011), bitter taste (Souza et al., 2013; Morais et al., 2014), and metallic taste (Rocha and Bolini, 2015). 
TDS

The TDS band plots for sucrose-, fructose-, and sucralose-sweetened beverages were similar (Figure 2a). They were characterized by dominant sweet taste, sweet aromatic, and cardboard flavor. Monk fruit beverages were characterized by initial dominant sweet taste followed by dominant, lingering metallic taste. Stevia beverages had the longest lingering dominant bitter taste followed by dominant and lingering metallic taste. All

a)

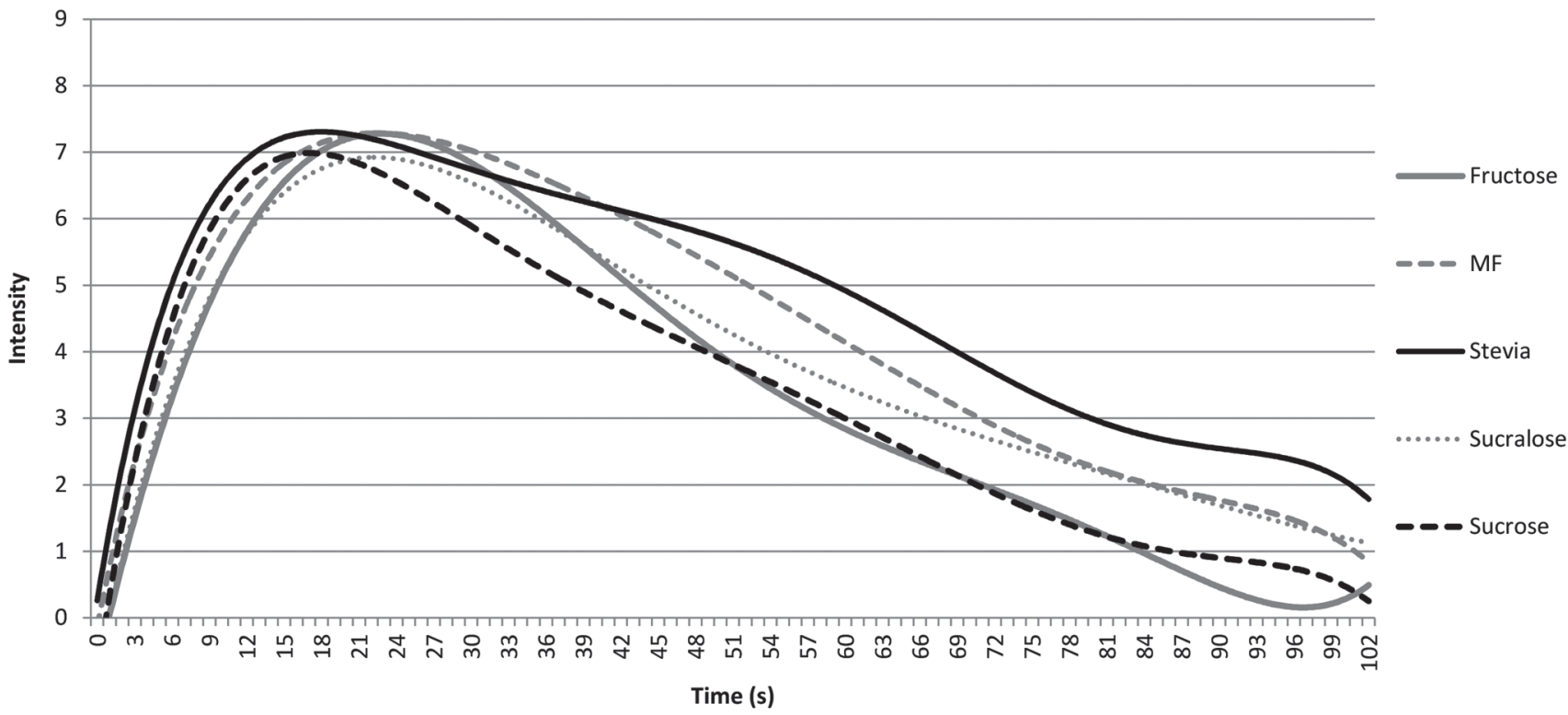

b)

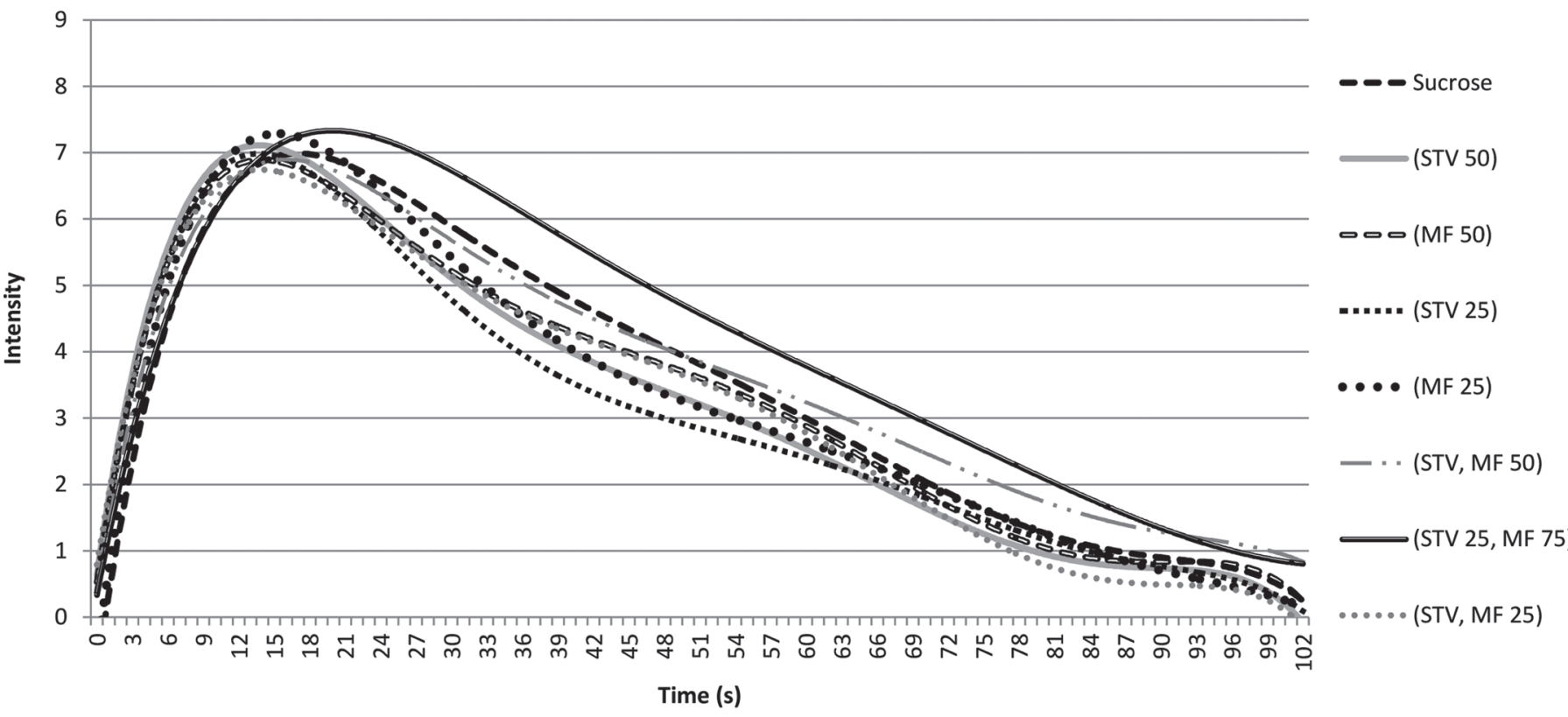

Figure 1. (a) Sweet taste time intensity curves for sweetened vanilla ready-to-mix protein beverages (nonblends). The reference beverage (7\% sucrose) is shown with a black, dashed line. Sweet taste intensity was scored on a 0- to 15-point scale (Meilgaard et al., 2007). (b) Sweet taste time intensity curves for sweetened vanilla ready-to-mix protein beverages with sweetener blends. The reference beverage $(7 \%$ sucrose) is shown with a black, dashed line. Sweet taste intensity was scored on a 0- to 15-point scale (Meilgaard et al., 2007). STV 50 = 50\% stevia, $50 \%$ fructose: MF $50=50 \%$ monk fruit, $50 \%$ fructose: STV $25=25 \%$ stevia, $75 \%$ fructose: MF $25=25 \%$ monk fruit, $75 \%$ fructose: STV, MF 50 $=50 \%$ stevia, $50 \%$ monk fruit; STV 25, MF $75=25 \%$ stevia, $75 \%$ monk fruit; STV, MF $25=25 \%$ stevia, $25 \%$ monk fruit, $50 \%$ fructose. (c) Bitter taste time intensity curves for sweetened vanilla ready-to-mix protein beverages. Bitter taste intensity was scored on a 0 - to 15 -point scale (Meilgaard et al., 2007). (d) Metallic taste time intensity curves for all sweetened vanilla ready-to-mix protein beverages. Metallic sensation was scored on a 0 - to 15-point scale (Meilgaard et al., 2007). 
natural sweetener blends displayed similar TDS curves and were characterized by dominant sweet taste only. Blends formulated with $50 \%$ or greater monk fruit or stevia displayed longer sweetness dominance than blends with $25 \%$ monk fruit or stevia. Of the beverages selected for consumer testing, dominant bitter taste was characterized only in stevia beverages (Figure 2a). These results were consistent with descriptive analy-

c)

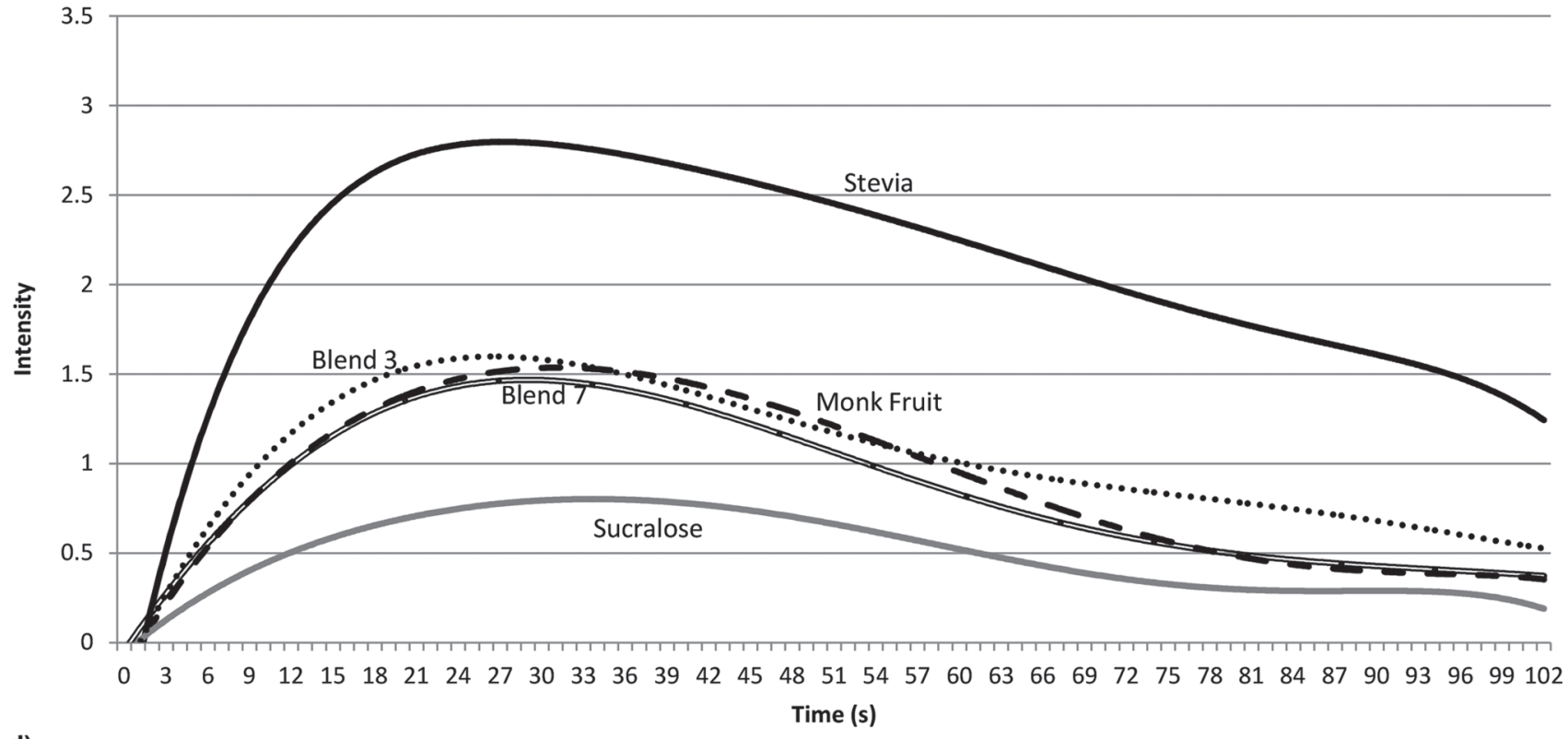

d)

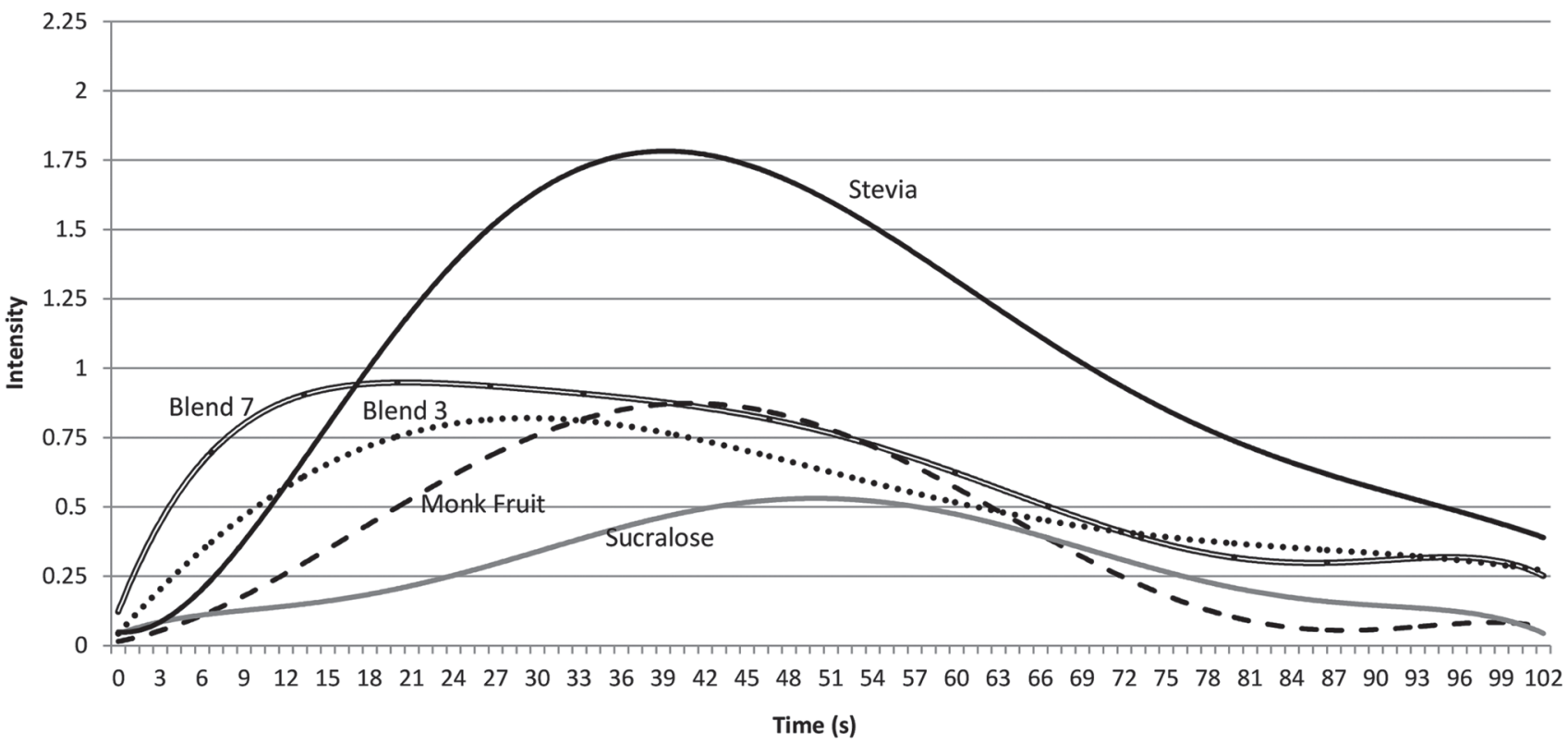

Figure 1 (Continued). (a) Sweet taste time intensity curves for sweetened vanilla ready-to-mix protein beverages (nonblends). The reference beverage ( $7 \%$ sucrose) is shown with a black, dashed line. Sweet taste intensity was scored on a 0- to 15-point scale (Meilgaard et al., 2007). (b) Sweet taste time intensity curves for sweetened vanilla ready-to-mix protein beverages with sweetener blends. The reference beverage (7\% sucrose) is shown with a black, dashed line. Sweet taste intensity was scored on a 0- to 15-point scale (Meilgaard et al., 2007). STV $50=50 \%$ stevia, $50 \%$ fructose; MF $50=50 \%$ monk fruit, $50 \%$ fructose; STV $25=25 \%$ stevia, $75 \%$ fructose; MF $25=25 \%$ monk fruit, $75 \%$ fructose; STV, MF $50=50 \%$ stevia, $50 \%$ monk fruit; STV 25, MF $75=25 \%$ stevia, $75 \%$ monk fruit; STV, MF $25=25 \%$ stevia, $25 \%$ monk fruit, $50 \%$ fructose. (c) Bitter taste time intensity curves for sweetened vanilla ready-to-mix protein beverages. Bitter taste intensity was scored on a 0- to 15-point scale (Meilgaard et al., 2007). (d) Metallic taste time intensity curves for all sweetened vanilla ready-to-mix protein beverages. Metallic sensation was scored on a 0 - to 15-point scale (Meilgaard et al., 2007). 
sis and TI results and provide additional information about the temporal differences in the sensory attributes of the beverages.

Previous studies reported similar TDS results for food and beverages formulated with nonnutritive sweeteners. Zorn et al. (2014) reported that sucralosesweetened orange juices had the most similar TDS curves to sucrose, and both samples were characterized by dominant sweet taste. Stevia-sweetened juices had dominant sweet taste followed by dominant bitter taste and dominant off flavor. Morais et al. (2014) reported that sucrose- and sucralose-sweetened chocolates were characterized by dominant sweet taste, and steviasweetened chocolates were characterized by dominant sweet taste followed by dominant bitter taste.

\section{TCATA}

The application of TCATA allowed further clarification of all attributes detected in the beverages because multiple attributes are selected by panelists. Bitter taste was documented in TCATA band plots for monk fruit-, sucralose-, and stevia-sweetened beverages as well as for 2 of the natural blends [blend $3(50 \%$ stevia/50\% monk fruit) and blend 7 (25\% stevia/75\% monk fruit); Figure 2b]. The temporality of bitter taste differed among beverages. It was longest lasting in stevia beverages, followed by monk fruit (Figure 2b). Metallic was detected in sucralose-, monk fruit-, and stevia-sweetened beverages as well as in the 2 blends previously mentioned and was again longest lasting in

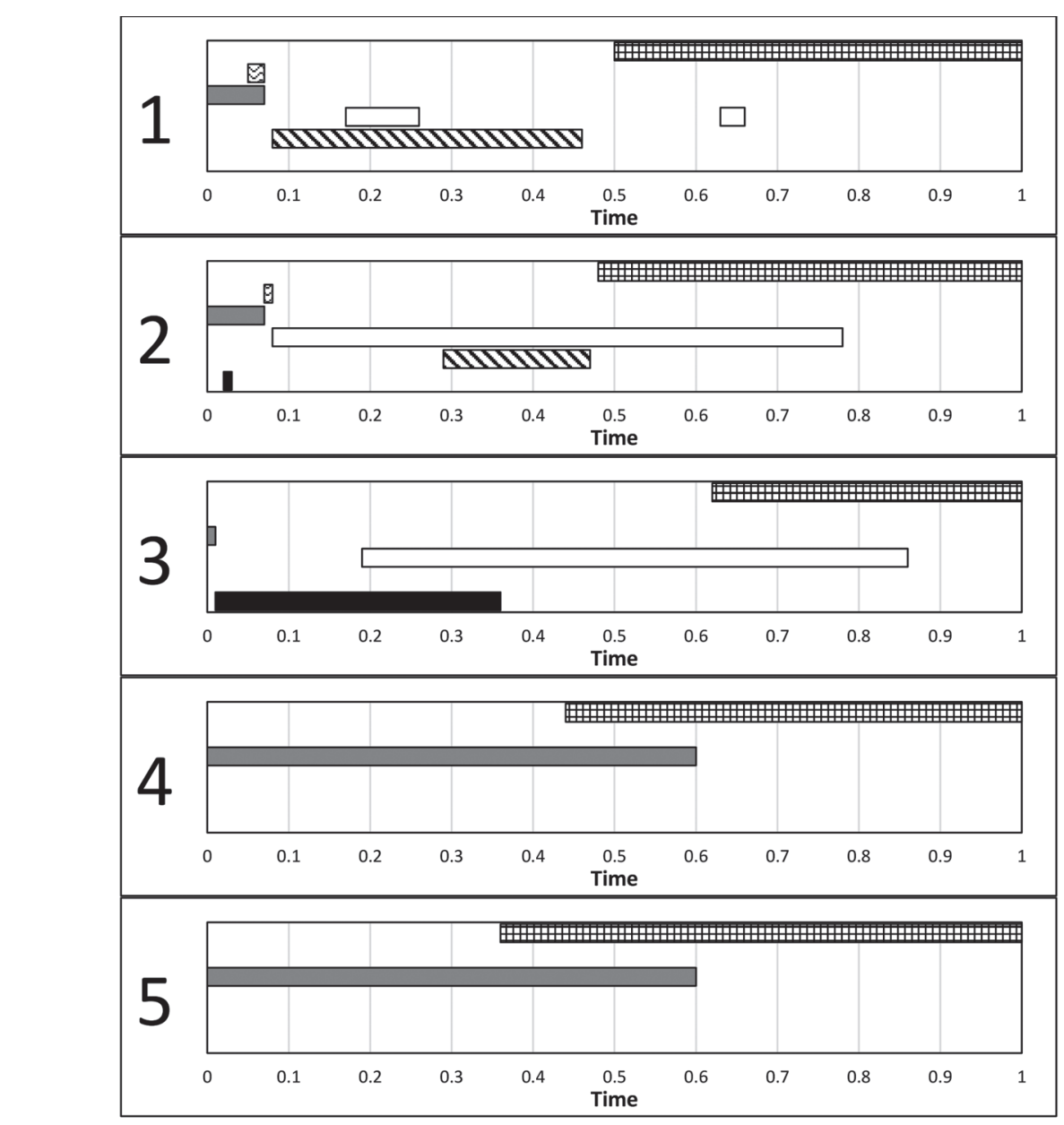

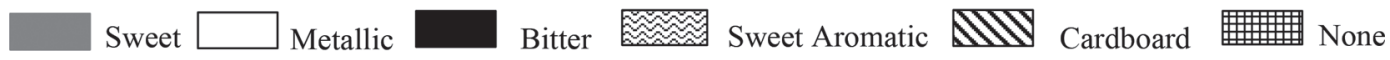

Figure 2. (a) Temporal dominance of sensations band plots for the 5 beverages selected for consumer testing. (b) Temporal check-all-thatapply band plots for the 5 beverages selected for consumer testing. Bands represent all detected attributes $(\alpha=0.05)$. Numbers indicate sweeteners. $1=$ sucralose control, $2=$ monk fruit control, $3=$ stevia control, $4=$ blend 7 ( $25 \%$ stevia $/ 75 \%$ monk fruit), $5=$ blend $4(25 \%$ stevia $/ 25 \%$ monk fruit $/ 50 \%$ fructose). 
stevia beverages followed by monk fruit beverages. Attributes of cardboard, sweet taste, and sweet aromatic were characterized in all beverages. Onset and duration of these attributes was similar for all beverages. The TCATA plots contained attributes not shown in TDS plots (addition of bitter and metallic in sucralose beverages, addition of bitter and sweet aromatic in monk fruit beverages, addition of cardboard and sweet aromatic in stevia beverages and blend 4, and addition of bitter, metallic, sweet aromatic, and cardboard in blend 7, indicating that these attributes were not dominant but still detected). These attributes were also documented in these beverages by descriptive analysis, so the TCATA results were consistent with descriptive analysis but also provide insights on temporal perception of these attributes. Ares et al. (2015) also reported differences between TDS and TCATA results for several product categories. These authors reported that TCATA delivered more detail about the sensory attributes present during evaluation and had higher discriminating power than TDS. These conclusions were supported by the results of this study as well.

\section{Consumer Acceptance Testing}

A total of 150 self-reported RTM protein powder consumers participated in the 2-d consumer acceptance test (60.7\% men, $39.3 \%$ women). Consumers were between the ages of 18 and $54 \mathrm{yr}$, with the majority between 18 and 34 yr (64.0\%). All consumers self-reported exercising at least once a week on average, with most reporting that they exercised 2 to 3 times per week
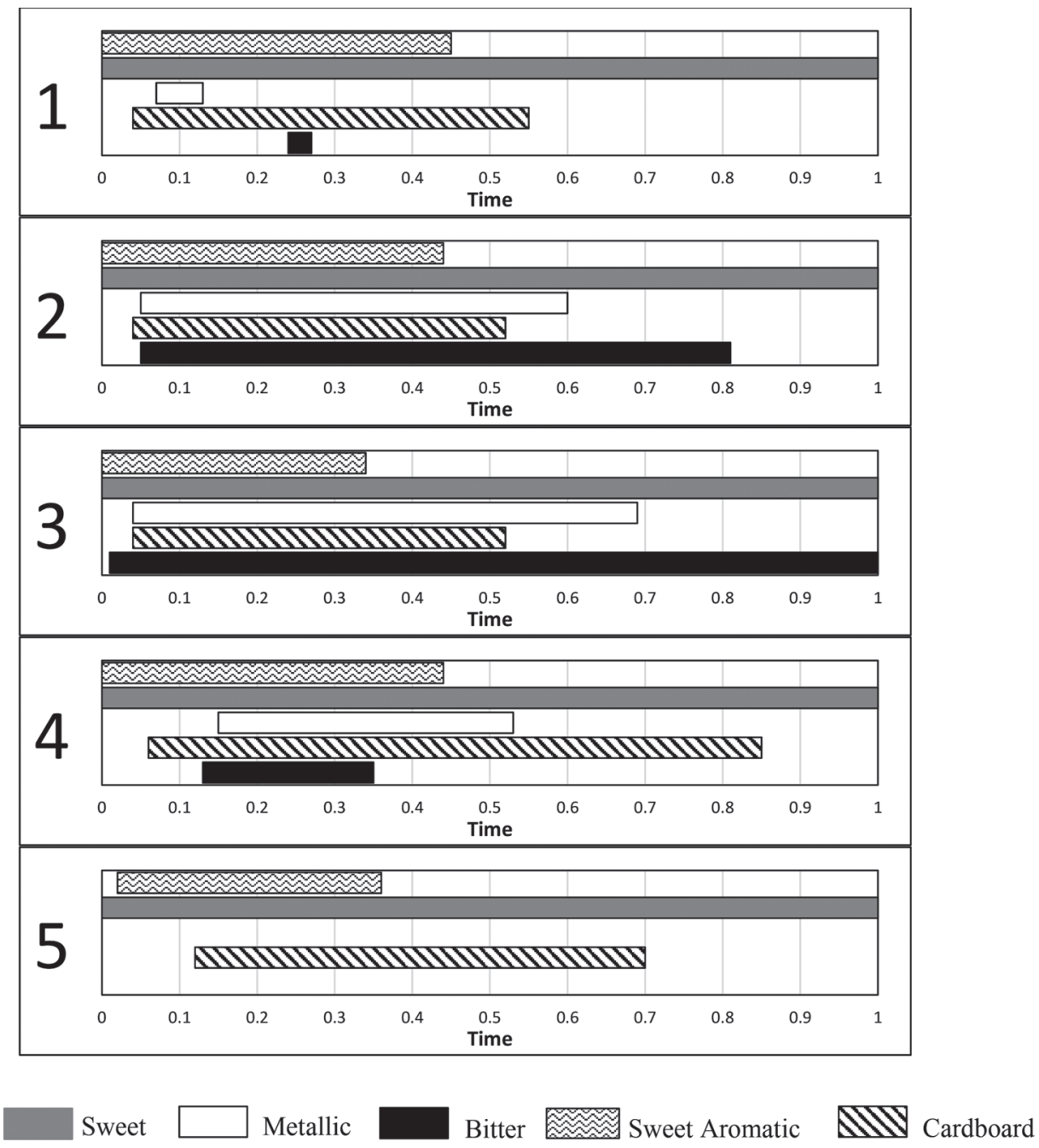

Figure 2 (Continued). (a) Temporal dominance of sensations band plots for the 5 beverages selected for consumer testing. (b) Temporal check-all-that-apply band plots for the 5 beverages selected for consumer testing. Bands represent all detected attributes $(\alpha=0.05)$. Numbers indicate sweeteners. $1=$ sucralose control, $2=$ monk fruit control, $3=$ stevia control, $4=$ blend 7 ( $25 \%$ stevia $/ 75 \%$ monk fruit), $5=$ blend 4 ( $25 \%$ stevia $/ 25 \%$ monk fruit $/ 50 \%$ fructose). 
$(31.3 \%)$ or 4 to 6 times per week $(46.0 \%)$. The majority of consumers $(66.0 \%)$ reported that a label claim of "naturally sweetened" was important to their RTM purchase decision, $48.7 \%$ reported reduced sugar was important, $42.7 \%$ reported sugar free as important, and $26.7 \%$ placed importance on a calorie-free sweetener in RTM purchase decision.

Cluster analysis of consumer scores for overall liking of sweetened protein beverages with and without priming statements identified 2 segments of consumers (Table 4). The interaction between sweetener, priming, and consumer segment was significant for overall liking, flavor liking, sweetness liking, vanilla flavor liking, and purchase intent $(P<0.05$; Table 4$)$. Segment 1 consumers $(\mathrm{n}=75)$ reported a less frequent consumption of both sucralose and acesulfame-K compared with segment 2 consumers $(\mathrm{n}=75 ; P<0.05)$. Segment 2 consumers scored primed sucralose samples higher than unprimed samples $(P<0.05$; Table 4$)$. Segment 1 consumers reacted more positively to priming statements about both natural sweetener blends with increased overall liking scores $(P<0.05)$, whereas segment 2 consumers scored primed and unprimed natural blends at parity $(P>0.05$; Figure 3$)$. These results suggest that segment 1 consumers were more label conscious, whereas segment 2 consumers were primarily flavor driven.

When asked concept liking of priming statements (before tasting), both segments scored sucralose lowest in concept liking $(P<0.05$; Table 4$)$. Once beverages were tasted, however, segment 2 consumers scored sucralose beverages highest in flavor liking, sweetness liking, and vanilla flavor liking. Segment 1 consumers, in contrast, scored sucralose beverages highest in flavor liking when unprimed but scored both natural-blend beverages highest in flavor liking, sweetness liking, and vanilla flavor liking when primed. Additionally, segment 1 consumers scored monk fruit concept liking, overall liking, flavor liking, and sweetness liking lower than that for other natural sweeteners or blends when primed $(P<0.05)$ but scored monk fruit overall liking, flavor liking, and sweetness liking at parity with sucralose, stevia, and blend 4 beverages when unprimed $(P>0.05)$. This may have been due to a negative reaction from the discriminative, label-conscious segment 1 consumers when shown an unfamiliar sweetener name. A 2015 survey reported that awareness and recognition of monk fruit were much lower than that of stevia or sucralose (Mintel Group Ltd., 2015). Only 10\% of survey respondents reported that they had used monk fruit as a sugar substitute compared with $25 \%$ for both stevia and sucralose. These results for concept and actual tasting collectively suggest that segment 1 consumers were more positively influenced by priming statements

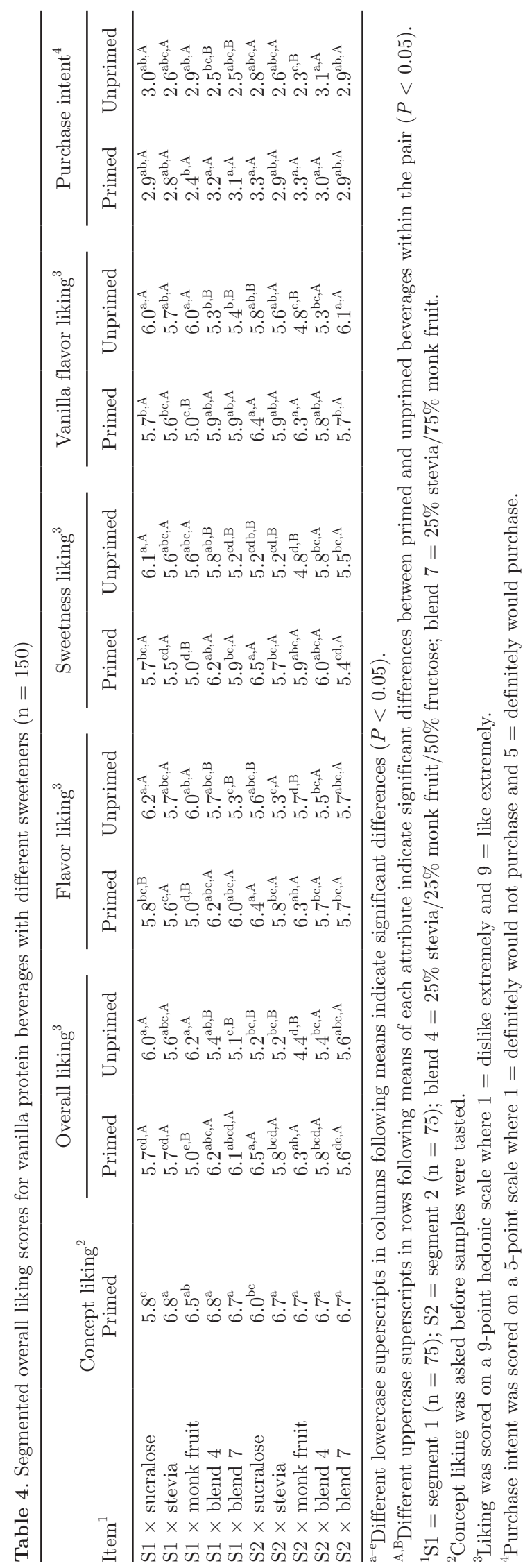


A)

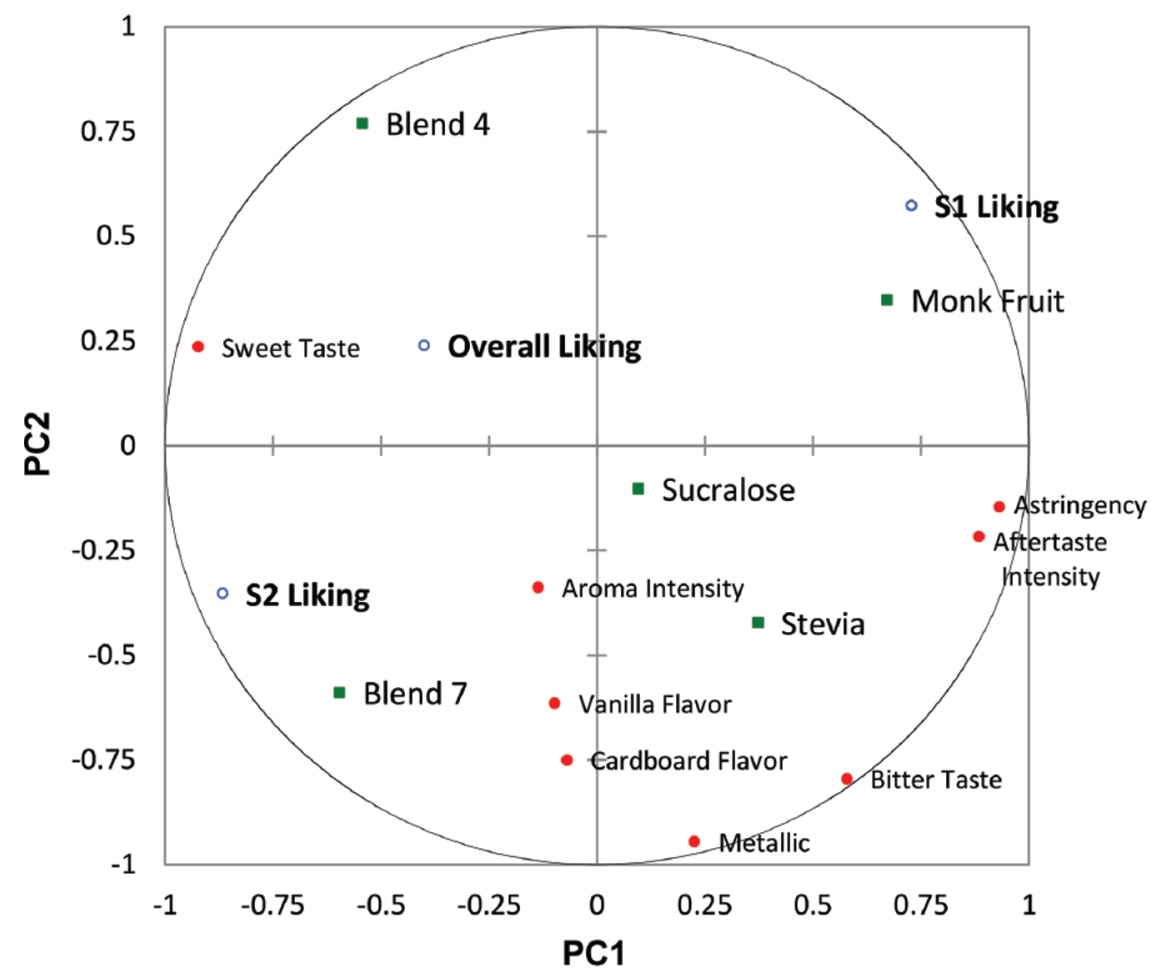

B)

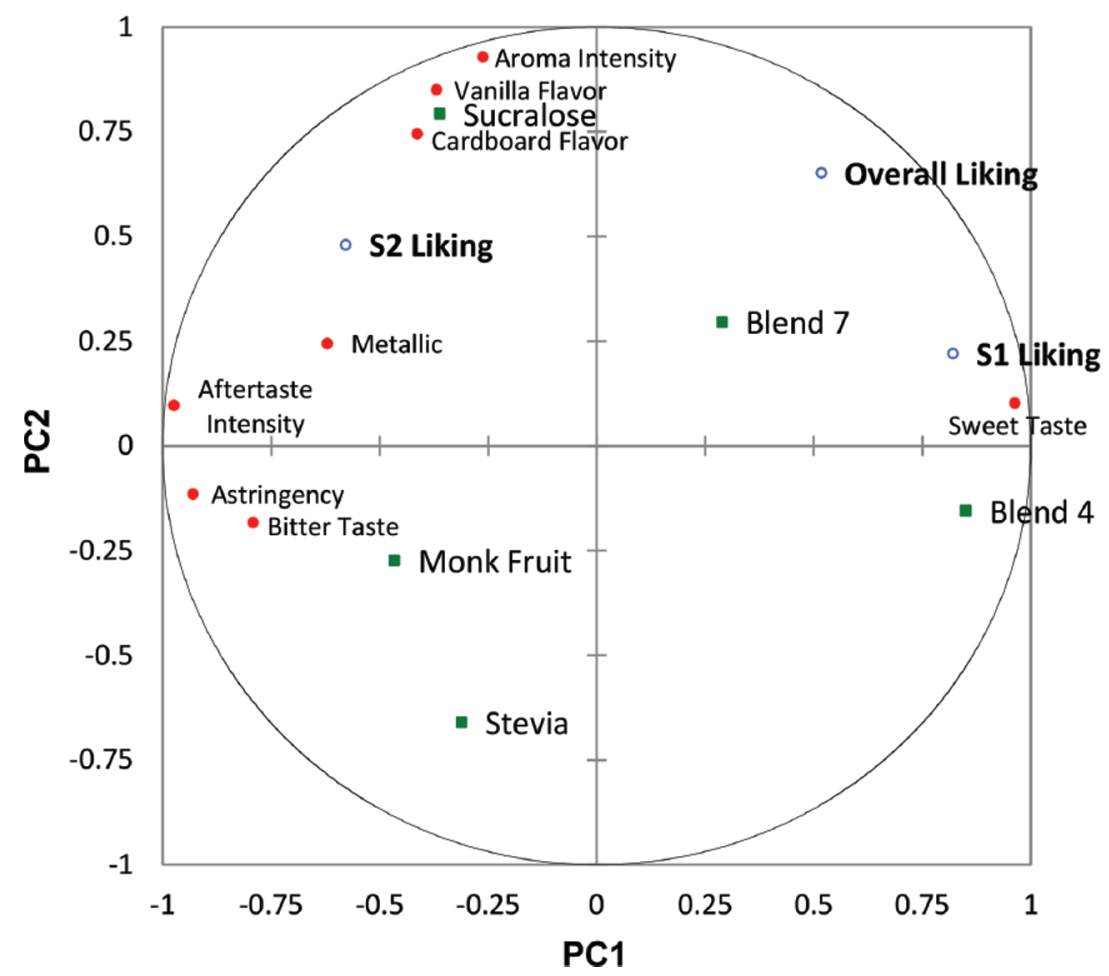

Figure 3. (a) Partial least squares regression biplot of unprimed overall liking scores of consumer segments for vanilla protein beverages with different sweeteners. Sensory attributes include aromatics and basic tastes. Variance explained as follows: PC1 $=48.1 \%$, PC2 $=17.0 \%$, and PC3 $=16.8 \% . \mathrm{PC}=$ principal component. (b) Partial least squares regression biplot of primed overall liking scores of consumer segments for vanilla protein beverages with different sweeteners. Sensory attributes include aromatics and basic tastes. Variance explained as follows: PC1 $=42.6 \%$, $\mathrm{PC} 2=23.4 \%$, and PC3 $=24.1 \%$. Blend $4=25 \%$ stevia $/ 25 \%$ monk fruit $/ 50 \%$ fructose; blend $7=25 \%$ stevia $/ 75 \%$ monk fruit; $\mathrm{S} 1=$ segment 1 $(\mathrm{n}=75) ; \mathrm{S} 2=$ segment $2(\mathrm{n}=75)$. Color version available online. 
about familiar natural sweeteners, whereas segment 2 consumers were most strongly influenced by beverage flavor.

Oltman et al. (2015) investigated the effect of priming statements ("great tasting" and protein content information) on overall liking of acidified whey protein beverages. Priming statements increased beverage concept liking $(P<0.05)$ but had no effect on overall liking $(P>0.05)$. Li et al. (2015) investigated parents' overall liking of reduced-sugar chocolate milks formulated with natural nonnutritive sweetener blends (in addition to sucrose) with and without priming statements that identified reduced-sugar and naturally sweetened milks. A label-conscious segment of consumers preferred sucrose-sweetened milks when the milks were tasted blind and conversely preferred natural nonnutritive sweetener blends when primed before tasting $(P<0.05)$, similar to results observed in the current study.

Overall liking and purchase intent of protein beverages with sweetener label claims were also evaluated independently of tasting. "Naturally sweetened" scored highest for overall liking and purchase intent $(P<$ $0.05)$. No significant differences were seen for sweetener label claim liking or purchase intent between consumer segments $(P<0.05)$. These results are consistent with findings from Oltman et al. (2015) that reported that sweetener type was the most important protein beverage attribute to one segment of consumers and that within sweetener type, "naturally sweetened" was the most appealing attribute. Li et al. (2014) reported that results of a conjoint survey indicated that sweetener type was the most important factor in parents' chocolate milk purchase. Natural, noncaloric sweeteners were most preferred by a health-conscious segment of parents, but flavor was ultimately more important to some consumers.

\section{CONCLUSIONS}

Two sugar-free and 5 reduced-sugar blends were formulated for application in RTM vanilla protein beverages. The reduced-sugar blends had reduced bitter and metallic off flavors compared with (sugar free) steviasweetened beverages. Of the 5 reduced-sugar blends, blend 4 (25\% stevia/25\% monk fruit/50\% fructose) most closely matched the temporal sensory properties of sucrose control beverages and offered a $>50 \%$ sugar reduction. Of the 2 noncaloric sugar-free blends, blend 7 (25\% stevia/75\% monk fruit) most closely matched the temporal sensory properties of sucrose control beverages. Consumer results supported these findings. Both reduced-sugar blends with fructose scored at parity with sucralose beverages $(P>0.05)$ for overall liking and flavor liking across all consumers in unprimed evaluations. Two distinct consumer segments were identified: label-conscious consumers and flavor-driven consumers. Segment 1 consumers (label conscious) were more discriminative when reading priming statements and were more interested in natural sweetener blends than segment 2 consumers. Segment 2 consumers (flavor driven) were ultimately influenced by beverage taste despite an interest in naturally sweetened beverages conceptually. Based on these results, naturally sweetened protein beverages (sugar free or reduced sugar) should be marketed with label claims but must also taste comparable with artificially sweetened or sucrosesweetened products. The findings from this study about the temporal sensory properties of natural, nonnutritive sweeteners and formulation of natural sweetener blends may be useful to beverage formulators in accomplishing this objective.

\section{ACKNOWLEDGMENTS}

Funding was provided in part by the National Dairy Council (Rosemont, IL).

\section{REFERENCES}

Ares, G., S. R. Jaeger, L. Antunez, L. Vidal, A. Gimenez, B. Coste, A. Picallo, and J. C. Castura. 2015. Comparison of TCATA and TDS for dynamic sensory characterization of food products. Food Res. Int. 78:148-158.

ASTM International. 2008. E2164-08: Standard Test Method for Directional Difference Test. ASTM International, West Conshohocken, PA.

ASTM International. 2012. E1697-05: Standard Test Method for Unipolar Magnitude Estimation of Sensory Attributes. ASTM International, West Conshohocken, PA.

Azevedo, B. M., M. Bruna, F. L. Schmidt, and H. Bolini. 2015. High-intensity sweeteners in espresso coffee: Ideal and equivalent sweetness and time-intensity analysis. Int. J. Food Sci. Technol. 50:1374-1381.

Blomstrand, E., and B. Saltin. 2001. BCAA intake affects protein metabolism in muscle after but not during exercise in humans. Am. J. Physiol. Endocrinol. Metab. 281:E365-E374.

Cadena, R. S., A. G. Cruz, J. A. F. Faria, and H. M. A. Bolini. 2012 Reduced fat and sugar vanilla ice creams: Sensory profiling and external preference mapping. J. Dairy Sci. 95:4842-4850.

Cardello, H. M. A. B., M. A. P. B. Da Silva, and H. M. Damasio. 1999. Measurement of the relative sweetness of stevia extract, aspartame and cyclamate/saccharin blend as compared to sucrose at different concentrations. Plant Foods Hum. Nutr. 54:119-130.

Castura, J. C., L. Antunez, A. Gimenez, and G. Ares. 2015. Temporal check-all-that-apply (TCATA): A novel dynamic method for characterizing products. Food Qual. Prefer. 47:79-90.

Childs, J. L., J. L. Thompson, J. S. Lillard, T. K. Berry, and M. Drake. 2008. Consumer perception of whey and soy protein in meal replacement products. J. Sens. Stud. 23:320-339.

Chollet, M., D. Gille, A. Schmid, B. Walther, and P. Piccinali. 2013 Acceptance of sugar reduction in flavored yogurt. J. Dairy Sci. 96:5501-5511.

Drake, M. A., Y. Karagul-yuceer, K. R. Cadwallader, G. V. Civille, and P. S. Tong. 2003. Determination of the sensory attributes of dried milk powders and dairy ingredients. J. Sens. Stud. 3:199-213.

Drake, M. A., R. E. Miracle, and J. M. Wright. 2009. Sensory properties of dairy proteins. Pages 429-448 in Milk Proteins: From 
Expression to Food. A. Thompson, M. Boland, and H. Singh, ed. Elsevier, Amsterdam, the Netherlands.

DuBois, G. E., and I. Prakash. 2012. Non-caloric sweeteners, sweetness modulators, and sweetener enhancers. Annu. Rev. Food Sci. Technol. 3:353-380.

Foegeding, E. A., and P. Luck. 2011. Whey protein products. Pages 873-878 in Encyclopedia of Dairy Sciences. J. W. Fuquay, P. F. Fox, and P. L. H. McSweeney, ed. Academic Press, London, UK.

Gerdes, S. 2012. Consumers have a thirst for protein beverages. Dairy Foods 113:22.

Goldsmith, L. A., and C. M. Merkel. 2001. Sucralose. Pages 185-207 in Alternative Sweeteners. 3rd rev. ed. L. O. B. Nabors, ed. CRC Press, Boca Raton, FL.

Guggisberg, D., P. Piccinali, and K. Schreier. 2011. Effects of sugar substitution with Stevia, Actilight and Stevia combinations or Palatinose on rheological and sensory characteristics of low-fat and whole milk set yoghurt. Int. Dairy J. 21:636-644.

Hanger, L. Y., A. Lotz, and S. Lepeniotis. 1996. Descriptive profiles of selected high intensity sweeteners (HIS), HIS blends, and sucrose. J. Food Sci. 61:456-459.

Hazen, C. 2003. Formulating function into beverages. Food Product Design 13:1-8.

Hoppert, K., S. Zahn, L. Janecke, R. Mai, S. Hoffmann, and H. Rohm. 2013. Consumer acceptance of regular and reduced-sugar yogurt enriched with different types of dietary fiber. Int. Dairy J. 28:1-7.

Hubbard, E. M., S. M. Jervis, and M. A. Drake. 2016. The effect of extrinsic attributes on liking of cottage cheese. J. Dairy Sci. 99:183-193.

Jacobson, J. 2015. Beverage survey finds "high protein," "natural" are top trends. Dairy Foods 116:16-17.

Kim, N. C., and A. D. Kinghorn. 2002. Highly sweet compounds of plant origin. Arch. Pharm. Res. 25:725-746.

Kinghorn, A. D., and C. M. Compadre. 2001. Less common high potency sweeteners. Pages 209-233 in Alternative Sweeteners. 3rd rev. ed. L. O. B. Nabors, ed. CRC Press, Boca Raton, FL.

Kinghorn, A. D., C. D. Wu, and D. D. Soejarto. 2001. Stevioside. Pages 167-184 in Alternative Sweeteners. 3rd rev. ed. L. O. B. Nabors, ed. CRC Press, Boca Raton, FL.

Labbe, D., P. Schlich, N. Pineau, F. Gilbert, and N. Martin. 2009. Temporal dominance of sensations and sensory profiling: A comparative study. Food Qual. Prefer. 20:216-221.

Lawless, H. T., and H. Heymann. 2010. Sensory Evaluation of Food: Principles and Practices. 2nd rev. ed. Springer Science and Business Media, New York, NY.

Le Reverend, F. M., C. Hidrio, A. Fernandes, and V. Aubry. 2008. Comparison between temporal dominance of sensations and time intensity results. Food Qual. Prefer. 19:174-178.

Li, X. E., K. Lopetcharat, and M. A. Drake. 2014. Extrinsic attributes that influence parents' purchase of chocolate milk for their children. J. Food Sci. 79:S1407-S1415.

Li, X. E., K. Lopetcharat, and M. A. Drake. 2015. Parents' and children's acceptance of skim chocolate milks sweetened by monk fruit and stevia leaf extracts. J. Food Sci. 80:S1083-S1092.

Lisak, K., M. Lenc, I. Jelicic, and R. Bozanic. 2012. Sensory evaluation of the strawberry flavored yoghurt with stevia and sucrose addition. Croatian J. Food Technol. Biotechnol. Nutr. 7:39-43.

Meilgaard, M., G. V. Civille, and B. T. Carr. 2007. Descriptive analysis techniques. Pages 161-170 in Sensory Evaluation Techniques. 4th ed. CRC Press, Boca Raton, FL.

Meillon, S., C. Urbano, and P. Schlich. 2009. Contribution of the Temporal Dominance of Sensations (TDS) method to the sensory de- scription of subtle differences in partially dealcoholized red wines. Food Qual. Prefer. 20:490-499.

Mintel Group Ltd. 2015.Sugar and Alternative Sweeteners-US-May 2015. Accessed Jul. 11, 2018. https://store.mintel.com/sugar-and -alternative-sweeteners-us-may-2015.

Morais, E. C., A. C. M. Pinheiro, C. A. Nunes, and H. M. A. Bolini. 2014. Multiple time-intensity analysis and temporal dominance of sensations of chocolate dairy dessert using prebiotic and different high-intensity sweeteners. J. Sens. Stud. 29:339-350.

Narayanan, P., B. Chinnasamy, L. Jin, and S. Clark. 2014. Use of justabout-right scales and penalty analysis to determine appropriate concentrations of stevia sweeteners for vanilla yogurt. J. Dairy Sci. 97:3262-3272.

Oliveira, D., L. Antunez, A. Gimenez, J. C. Castura, R. Deliza, and G. Ares. 2015. Sugar reduction in probiotic chocolate-flavored milk: Impact on dynamic sensory profile and liking. Food Res. Int. $75: 148-156$

Oltman, A. E., K. Lopetcharat, E. Bastian, and M. A. Drake. 2015. Identifying key attributes for protein beverages. J. Food Sci. 80:S1383-S1390.

Palazzo, A. B., M. A. R. Carvalho, P. Efraim, and H. M. A. Bolini. 2011. The determination of isosweetness concentrations of sucralose, rebaudioside and neotame as sucrose substitutes in new diet chocolate formulations using the time-intensity analysis. J. Sens. Stud. 26:291-297.

Pawar, R. S., A. J. Krynitsky, and J. I. Rader. 2013. Sweeteners from plants - with emphasis on Stevia rebaudiana (Bertoni) and Siraitia grosvenorii (Swingle). Anal. Bioanal. Chem. 405:4397-4407.

Philippe, R. N., M. De Mey, J. Anderson, and P. K. Ajikumar. 2014. Biotechnological production of natural zero-calorie sweeteners. Curr. Opin. Biotechnol. 26:155-161.

Pineau, N., P. Schlich, S. Cordelle, C. Mathonniere, S. Issanchou, A. Imbert, M. Rogeaux, P. Etievant, and E. Koster. 2009. Temporal dominance of sensations: Construction of the TDS curves and comparison with time-intensity. Food Qual. Prefer. 20:450-455.

Reis, R. C., V. P. Minim, H. Bolini, B. R. Dias, L. A. Minim, and E. Ceresino. 2011. Sweetness equivalence of different sweeteners in strawberry-flavored yogurt. J. Food Qual. 34:163-170.

Rocha, I. F. O., and H. M. A. Bolini. 2015. Passion fruit juice with different sweeteners: Sensory profile by descriptive analysis and acceptance. Food Sci. Nutr. 3:129-139.

Russell, T. A., M. A. Drake, and P. D. Gerard. 2006. Sensory properties of whey and soy proteins. J. Food Sci. 71:S447-S455.

Savita, S. M., K. Sheela, S. Sunanda, A. G. Shankar, and P. Ramakrishna. 2004. Stevia rebaudiana - A functional component for food industry. J. Hum. Ecol. 15:261-264.

Souza, V. R., P. A. Pereira, A. C. M. Pinheiro, H. Bolini, S. V. Borges, and F. Queiroz. 2013. Analysis of various sweeteners in low-sugar mixed fruit jam: Equivalent sweetness, time-intensity analysis and acceptance test. Int. J. Food Sci. Technol. 48:1541-1548.

White, J. S., and T. F. Osberger. 2001. Crystalline fructose. Pages 367-390 in Alternative Sweeteners. 3rd rev. ed. L. O. B. Nabors, ed. CRC Press, Boca Raton, FL.

Wright, J. M., M. E. Carunchia Whetstine, R. E. Miracle, and M. Drake. 2006. Characterization of a cabbage off-flavor in whey protein isolate. J. Food Sci. 71:C86-C90.

Zorn, S., F. Alcaire, L. Vidal, A. Gimenez, and G. Ares. 2014. Application of multiple-sip temporal dominance of sensations to the evaluation of sweeteners. Food Qual. Prefer. 36:135-143. 